\title{
Mortality in chronic kidney disease patients with COVID-19: a systematic review and meta-analysis
}

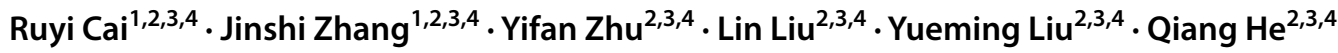

Received: 13 August 2020 / Accepted: 2 December 2020 / Published online: 3 January 2021

(c) The Author(s) 2021

\begin{abstract}
At the beginning of 2020, the outbreak of coronavirus disease 2019 (COVID-19) led to a worldwide pandemic and mass panic. The number of infected people has been increasing exponentially since, and the mortality rate has also been concomitantly increasing. At present, no study has summarized the mortality risk of COVID-19 in patients with chronic kidney disease (CKD). Therefore, the aim of the present study was to conduct a literature review and meta-analysis to understand the frequency of mortality among CKD patients infected with COVID-19. A comprehensive systematic search was conducted on the PubMed, Embase, and Cochrane databases to find articles published until May 15, 2020. Study quality was assessed using a modified version of the Newcastle-Ottawa Scale. After careful screening based on the inclusion and exclusion criteria, 3,867,367 patients from 12 studies were included. The mortality rate was significantly higher among CKD patients with COVID-19 infection than among CKD patients without COVID-19 infection, as indicated by a pooled OR of 5.81 (95\% CI $\left.3.78-8.94, P<0.00001, I^{2}=30 \%\right)$. The patients were then stratified into $\geq 70$ and $<70$ years, and subgroup analysis revealed that among CKD patients with COVID-19 infection, the mortality rate was higher in the $<70$ years group (OR $8.69,95 \%$ CI $7.56-9.97, P<0.0001)$ than in the $\geq 70$ years group $(O R 2.44,95 \%$ CI $0.75-6.63, P=0.15)$. Thus, COVID-19 patients with $\mathrm{CKD}$ have a high mortality risk and require a comprehensive multidisciplinary management strategy.
\end{abstract}

Keywords COVID-19 $\cdot$ SARS-CoV-2 $\cdot$ Chronic kidney disease $\cdot$ Mortality

\section{Introduction}

In December 2019, the first outbreak of coronavirus disease (COVID-19) caused by severe acute respiratory syndrome novel beta-coronavirus (SARS-CoV-2) was reported in Wuhan, China [1]. Since then, the novel coronavirus has dealt a severe blow to the global health care industry and led to mass panic all over the world [2]. As of July 1, 2020,

Qiang $\mathrm{He}$

qianghe1973@126.com

1 School of Medicine, Hangzhou Normal University, Hangzhou, Zhejiang 310018, People's Republic of China

2 Department of Nephrology, Zhejiang Provincial People's Hospital, People's Hospital of Hangzhou Medical College, Hangzhou, Zhejiang 310014, People's Republic of China

3 People's Hospital of Hangzhou Medical College, Hangzhou, Zhejiang 310014, People's Republic of China

4 Chinese Medical Nephrology Key Laboratory of Zhejiang Province, Hangzhou, Zhejiang 310014, People's Republic of China a total of 10,596,241 confirmed cases and 514,242 deaths were reported across 212 countries (source: World Health Organization website), and the number of confirmed cases and deaths continues to rise. SARS-CoV-2 is mainly transmitted from person to person through respiratory droplets, which are usually released when an infected person coughs or sneezes. Its main clinical manifestations are fever, cough, myalgia, malaise, and diarrhea [3,4]. The diagnosis of COVID-19 is usually based on PCR detection of SARS$\mathrm{CoV}-2$ in nasopharyngeal swabs or other specimens [5].

Patients with severe disease may present with dyspnea, a respiratory rate higher than 30 breaths per minute, blood oxygen saturation less than $93 \%$, a $\mathrm{PaO}_{2}: \mathrm{FiO}_{2}$ ratio $\leq 300 \mathrm{~mm} \mathrm{Hg}$, and invasion of more than $50 \%$ of the lung fields within $24-48 \mathrm{~h}$ of symptom onset [6]. In patients with COVID-19, comorbidities (including cardiovascular disease, chronic kidney disease, diabetes, and other chronic diseases) are associated with a higher risk of severe complications and death [7]. In particular, chronic kidney disease (CKD) is associated with an increase in the hospitalization rate of patients with novel coronavirus-associated 
pneumonia, and the mortality rate seems to be 14-16 times higher than that of the general population [8]. Additionally, a meta-analysis suggested that CKD should be considered as an important risk factor for COVID-19 [9], and Cheng et al. showed that COVID-19 patients had a high prevalence of kidney disease at admission and a high in-hospital mortality rate [10]. Therefore, there is an urgent need to understand the risks in patient populations with such co-morbidities. This meta-analysis responds to this need by focusing on studies that report the risk of clinical death in patients with CKD complicated with COVID-19 and evaluating the reliability of the evidence. The purpose of this article is to explore the frequency of clinical deaths in patients with CKD complicated with COVID-19.

\section{Methods}

\section{Search strategy}

This meta-analysis was conducted and reported in accordance with the Preferred Reporting Items for Systematic Reviews and Meta-Analysis and Meta-Analysis of Observational Studies in Epidemiology (PRISMA) guidelines [11]. To find the relevant studies, two authors (RY Cai and JS Zhang) conducted a comprehensive search of the PubMed, EMBASE, and Cochrane databases for studies published as of May 15, 2020. The search terms used were "coronavirus," "COVID-19," "SARS-CoV-2," "mortality," "outcomes," "chronic kidney disease," and "chronic renal disease." The reference lists of the eligible articles were also reviewed to search for relevant articles. The supervising authors reviewed the included studies and data.

\section{Inclusion and exclusion criteria}

This review only includes studies on humans that were published in English and reported confirmed cases of COVID19 in patients with CKD, with data for both survivors and non-survivors. Studies that were published in duplicate, case reports, reviews, and letters were excluded, as were studies that focused only on the mortality rate of CKD or only on COVID-19. Two authors (RY Cai and JS Zhang) independently screened the titles and abstracts of all potentially relevant studies and reviewed the full text of the articles that met the inclusion criteria.

\section{Data extraction and quality check}

The following features were extracted from the relevant articles: first author's name, country, source of data, sample size, and age and gender of both survivors and nonsurvivors. The quality of the studies was assessed using the Newcastle-Ottawa scale (NOS) [12]. Quality assessment was independently conducted by two authors (RY Cai and JS Zhang), and any disagreement was resolved via discussion.

\section{Statistical analysis}

Our meta-analysis was performed with Review Manager 5.3. Heterogeneity was assessed by calculating the $I^{2}$ index. The fixed- or random-effects model was utilized, as appropriate. Sensitivity analysis was used to evaluate the impact of each study by eliminating studies one at a time or alternating between random-effects and fixed-effects models. The findings from the meta-analysis are graphically represented by a forest plot. Publication bias was determined and presented using a funnel plot. For categorical outcomes, an odds ratio (OR) with 95\% CI (for observational studies) was calculated for each study. The pooled odds ratios (ORs) of different studies and the corresponding 95\% confidence intervals (CIs) were used to estimate the frequency of clinical deaths in patients with CKD complicated with COVID19. All p-values in this study were two tailed, and statistical significance was set at $\leq 0.05$.

\section{Results}

\section{Characteristics of the included studies}

A total of 3348 articles were selected from the databases, but 268 were excluded because of duplication. The titles and abstracts of the articles were screened, and 2877 were excluded because they did not meet the inclusion criteria. After the full text of the articles was read, 191 articles with inconsistent data were deleted. Finally, 12 articles that met all the inclusion criteria were included [13-24]. The selection process is depicted in Fig. 1, and the common baseline characteristics of the patients are shown in Table 1 . The NOS score of the included studies was $7-8$, and the quality of the articles was evaluated as high (Table 2).

\section{Pooled analysis}

The forest plot of mortality in patients with CKD infected with COVID-19 is shown in Fig. 2. REM analysis showed that CKD patients with COVID-19 had a higher mortality rate (pooled OR 5.81, 95\% CI 3.78-8.94, $P<0.00001$, $I^{2}=30 \%$ ). As shown in Fig. 2, although most of the samples were from the UK, this did not create a bias in the study results. 


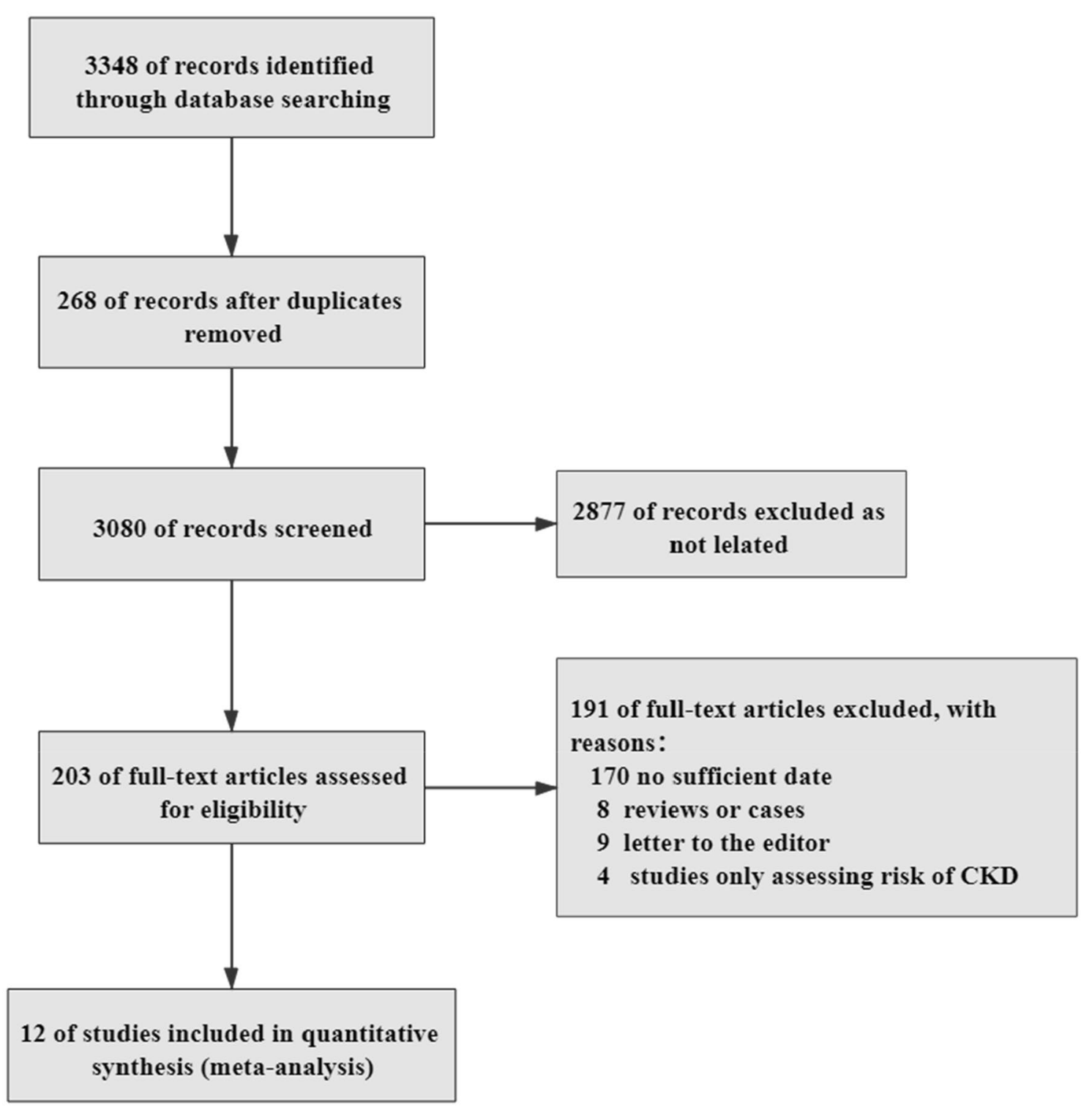

Fig. 1 Flow chart depicting the search strategy to identify articles on the relationship between CKD and the mortality of patients with COVID19

\section{Subgroup analysis and sensitivity analysis}

Patients were divided into two subgroups according to their age: $\geq 70$ years and $<70$ years. The results of the two groups were significantly different $(\geq 70$ years: OR 2.44, 95\% CI $0.75-6.63, P=0.15 ;<70$ years: OR $8.69,95 \%$ CI 7.56-9.97, $P<0.0001$ ) (Fig. 3). When all the studies were analyzed, low heterogeneity was observed $\left(I^{2}=30 \%\right)$, but after the studies of Chen and Wang were excluded, the heterogeneity decreased significantly $\left(I^{2}=2 \%\right)$. Therefore, Chen and Wang's study may be responsible for the heterogeneity of this meta-analysis. There was no evidence of a publication bias, according to the findings of funnel plot analysis (Fig. 4).

\section{Discussion}

This study presents a literature review and meta-analysis of the information reported so far on the mortality rate of CKD patients with COVID-19. According to the literature review in the current study, no meta-analysis has analyzed the mortality of CKD patients with COVID-19. Nonetheless, based on the data of the relevant studies extracted from the literature, our research found that COVID-19 infection was closely associated with mortality in CKD patients. Although cardiovascular disease is the leading cause of death in CKD, the death rate associated with pulmonary infection in CKD patients is also high [25, 26]. Our findings confirm this, as the CKD patients with COVID-19 infection 
Table 1 Baseline characteristics of studies included in the systematic review

\begin{tabular}{|c|c|c|c|c|c|}
\hline Author & Source of data & Country & $\operatorname{Dead}(n, \%)$ & $\begin{array}{l}\text { Mean/median } \\
\text { age (years) }\end{array}$ & Female $(\%)$ \\
\hline \multicolumn{6}{|l|}{ Age $\geq 70$ years } \\
\hline Chen et al. [22] & Zhongnan Hospital of Wuhan University & China & $19,34.55 \%$ & 74 & 38.18 \\
\hline Wang et al. [15] & Renmin Hospital of Wuhan University & China & $65,19.17 \%$ & 71 & 51.03 \\
\hline \multicolumn{6}{|l|}{ Age $<70$ years } \\
\hline Banerjee et al. [24] & Hospitals in UK & England & $38,847,1.01 \%$ & 48 & 50.70 \\
\hline Cao et al. [23] & $\begin{array}{l}\text { Wuhan University } \\
\text { Zhongnan Hospital }\end{array}$ & China & $17,16.67 \%$ & 54 & 48.04 \\
\hline Chen et al. [21] & Tongji Hospital & China & $113,41.54 \%$ & 62 & 37.87 \\
\hline Nikpouraghdam et al. [20] & Baqiyatallah Hospital & China & $239,8.06 \%$ & 56 & 34.04 \\
\hline Ruan et al. [19] & Tongji Hospital & China & $68,45.33 \%$ & 58.5 & 32 \\
\hline Shi et al. [17] & Renmin Hospital of Wuhan University & China & $62,9.24 \%$ & 63 & 52.01 \\
\hline Shi et al. [18] & $\begin{array}{l}\text { Renmin Hospital of Wuhan } \\
\text { Zhongnan Hospital }\end{array}$ & China & $47,15.36 \%$ & 64.5 & 50.98 \\
\hline Wang et al. [16] & $\begin{array}{l}\text { Zhongnan Hospital } \\
\text { Xishui Hospital }\end{array}$ & China & $19,17.76 \%$ & 51 & 46.73 \\
\hline Yan et al. [14] & Tongji Hospital & China & $108,54.55 \%$ & 64 & 39.90 \\
\hline Zhou et al. [13] & $\begin{array}{l}\text { Jinyintan Hospital } \\
\text { Wuhan Pulmonary Hospital }\end{array}$ & China & $54,28.27 \%$ & 56 & 37.70 \\
\hline
\end{tabular}

Table 2 Newcastle-Ottawa score of the included studies

\begin{tabular}{|c|c|c|c|c|c|c|c|c|c|}
\hline Study ID & $\begin{array}{l}\text { Exposed } \\
\text { cohort repre- } \\
\text { sentative }\end{array}$ & $\begin{array}{l}\text { Non-exposed } \\
\text { cohort selected } \\
\text { from same } \\
\text { source }\end{array}$ & $\begin{array}{l}\text { Exposure } \\
\text { ascertained }\end{array}$ & $\begin{array}{l}\text { Outcome of } \\
\text { study was not } \\
\text { present at start } \\
\text { of the study }\end{array}$ & $\begin{array}{l}\text { Com- } \\
\text { para- } \\
\text { bility }\end{array}$ & $\begin{array}{l}\text { Adequate } \\
\text { assess- } \\
\text { ment }\end{array}$ & $\begin{array}{l}\text { Follow-up } \\
\text { was long } \\
\text { enough }\end{array}$ & $\begin{array}{l}\text { Adequate } \\
\text { follow-up }\end{array}$ & Quality score \\
\hline Chen et al. [22] & Yes & Yes & Yes & Yes & 0 & Yes & Yes & Yes & 7 \\
\hline $\begin{array}{l}\text { Wang et al. } \\
\text { [15] }\end{array}$ & Yes & Yes & Yes & Yes & 0 & Yes & Yes & Yes & 7 \\
\hline $\begin{array}{l}\text { Banerjee et al. } \\
{[24]}\end{array}$ & Yes & Yes & Yes & Yes & 0 & Yes & Yes & Yes & 7 \\
\hline Cao et al. [23] & Yes & Yes & Yes & Yes & 0 & Yes & Yes & Yes & 7 \\
\hline Chen et al. [21] & Yes & Yes & Yes & Yes & 1 & Yes & Yes & Yes & 8 \\
\hline $\begin{array}{l}\text { Nikpouragh- } \\
\text { dam et al. } \\
{[20]}\end{array}$ & Yes & Yes & Yes & Yes & 0 & Yes & Yes & Yes & 7 \\
\hline Ruan et al. [19] & Yes & Yes & Yes & Yes & 0 & Yes & Yes & Yes & 7 \\
\hline Shi et al. [17] & Yes & Yes & Yes & Yes & 0 & Yes & Yes & Yes & 7 \\
\hline Shi et al. [18] & Yes & Yes & Yes & Yes & 0 & Yes & Yes & Yes & 7 \\
\hline $\begin{array}{l}\text { Wang et al. } \\
{[16]}\end{array}$ & Yes & Yes & Yes & Yes & 0 & Yes & Yes & Yes & 7 \\
\hline Yan et al. [14] & Yes & Yes & Yes & Yes & 0 & Yes & Yes & Yes & 7 \\
\hline Zhou et al. 13 & Yes & Yes & Yes & Yes & 0 & Yes & Yes & Yes & 7 \\
\hline
\end{tabular}

had a higher mortality rate than those without COVID-19 infection (pooled OR 5.81). This is probably because in CKD patients, the levels of pro-inflammatory cytokines are increased, and this leads to an increase in oxidative stress that eventually produces an inflammatory immune response. The resulting immune system damage may increase susceptibility to bacterial and viral infections, and this might be the main reason for the increased risk of pulmonary inflammation [27]. When the patients in the current metaanalysis were stratified into those older than 70 years and those younger than 70 years $(\geq 70$ years: OR $2.44,95 \% \mathrm{CI}$ $0.75-6.63, P=0.15 ;<70$ years: OR $8.69,95 \%$ CI $7.56-9.97$, 


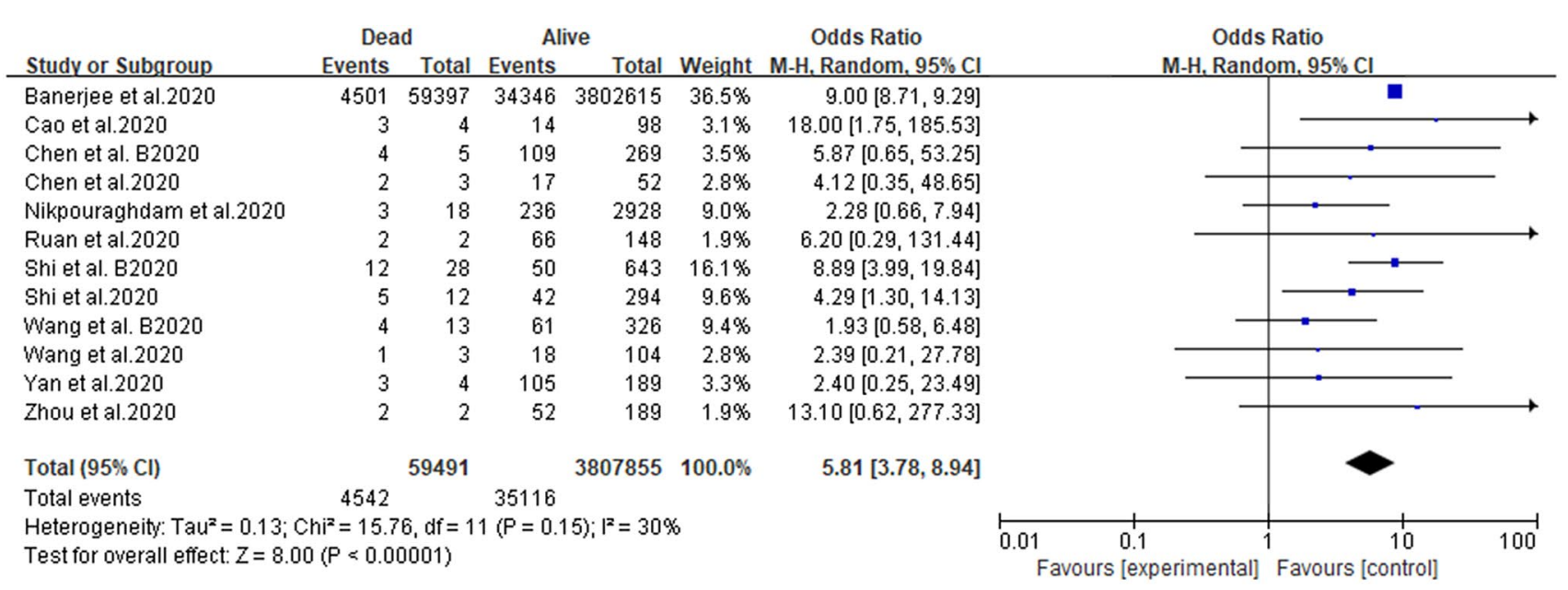

Fig. 2 Forest plot depicting the relationship between CKD and the mortality of patients with COVID-19

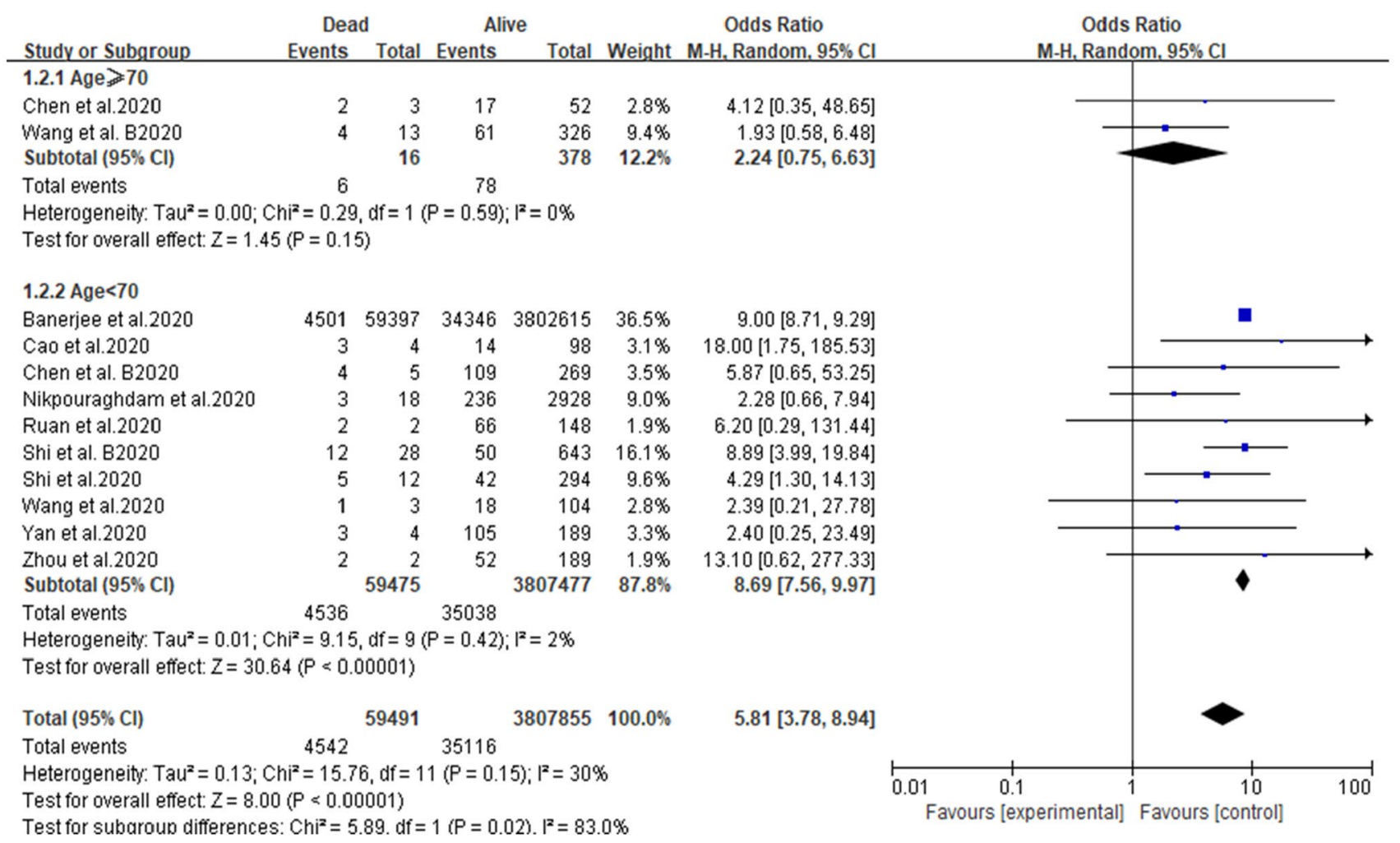

Fig. 3 Forest plot depicting the relationship between CKD and the mortality of COVID-19 patients after subgroup analysis according to age

$P<0.0001$ ), we found that among CKD patients complicated with COVID-19, those younger than 70 years had a higher mortality rate than those who were 70 years or older. This is probably because elderly patients are more likely to have other complications (such as hypertension, diabetes, coronary heart disease, and COPD). These comorbidities will increase the risk of death associated with COVID-19 in the elderly, so the specific condition associated with the increased risk of death in CKD patients is not clear. Moreover, the high mortality rate in elderly patients is probably related to the higher incidence of these comorbidities, rather than CKD [28]. However, misdiagnosis or delayed diagnosis of COVID-19 is common in elderly patients with CKD, on account of low immune response, mild clinical symptoms, and atypical CT imaging findings of the chest [29]. This may explain why an increase in mortality is not found in 


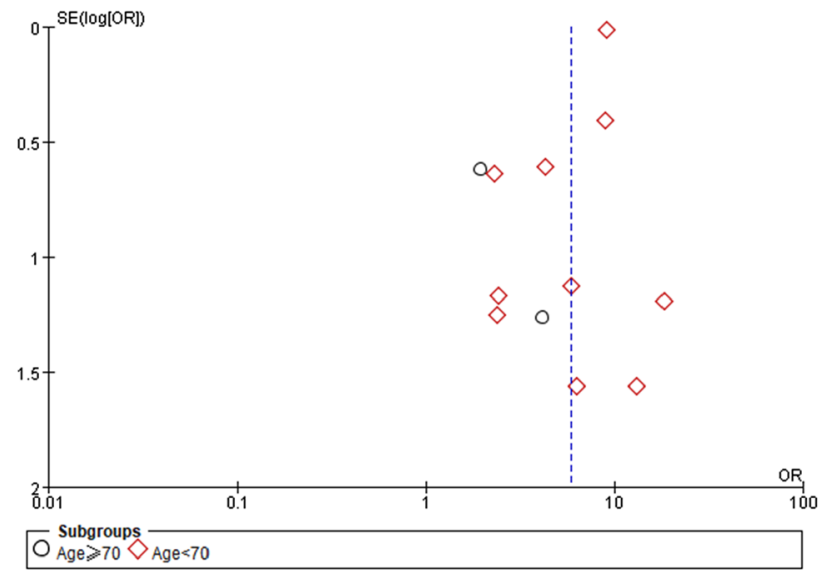

Fig. 4 Funnel plot depicting publication bias

elderly CKD patients with COVID-19 infection. As CKD can be prevented and treated to a large extent, it deserves more attention in health policy decision-making globally. Therefore, it is necessary to establish a comprehensive disease management strategy that includes lifestyle, nutrition, medications, and other methods to reduce the mortality rate of CKD patients.

Our study has several limitations. One of the main limitations is that there were no data about the disease stage of the CKD patients, the disease course, and the drugs that were administered. Second, the data were not adjusted for confounding factors, such as gender, race, and BMI, which may have affected the results. Third, CKD patients with COVID19 may have other chronic diseases (such as hypertension, diabetes, COPD, and cardiovascular and cerebrovascular diseases) that may have affected the results, but the related data were not considered in the analysis. Fourth, the age stratification carried out was not comprehensive enough.

\section{Conclusion}

The results of the present meta-analysis on the limited published data indicate that regardless of age, CKD patients with COVID-19 infection have a high mortality risk. Thus, CKD patients infected with SARS-CoV-2 must be carefully monitored and managed to lower the risk of death.

Acknowledgments We would like to thank Dr. Zhou, Dr. Yan, Dr. Wang, Dr. Wang, Dr. Shi, Dr. Shi, Dr. Ruan, Dr. Nikpouraghdam, Dr. Chen, Dr. Chen, and Dr. Cao for providing data for this study.

Funding This work was supported by the General Project Funds from the Health Department of Zhejiang Province (Grant No. 2017KY213) and the Natural Science Foundation of Zhejiang Province (Grant No. LQ19H050003).
Data availability All data needed to evaluate the conclusions in the paper are present in the paper.

\section{Compliance with ethical standards}

Conflict of interest The authors declare that there is no conflict of interest regarding the publication of this paper.

Open Access This article is licensed under a Creative Commons Attribution 4.0 International License, which permits use, sharing, adaptation, distribution and reproduction in any medium or format, as long as you give appropriate credit to the original author(s) and the source, provide a link to the Creative Commons licence, and indicate if changes were made. The images or other third party material in this article are included in the article's Creative Commons licence, unless indicated otherwise in a credit line to the material. If material is not included in the article's Creative Commons licence and your intended use is not permitted by statutory regulation or exceeds the permitted use, you will need to obtain permission directly from the copyright holder. To view a copy of this licence, visit http://creativecommons.org/licenses/by/4.0/.

\section{References}

1. Wang D, Hu B, Hu C et al (2020) Clinical characteristics of 138 hospitalized patients with 2019 novel coronavirus-infected pneumonia in Wuhan, China [J]. JAMA 323(11):1061

2. Phelan AL, Katz R, Gostin LO (2020) The Novel Coronavirus Originating in Wuhan, China: Challenges for Global Health Governance [J]. JAMA 323(8):709-710

3. Chen NS, Zhou M, Dong X et al (2020) Epidemiological and clinical characteristics of 99 cases of 2019 novel coronavirus pneumonia in Wuhan, China: a descriptive study [J]. Lancet 395(10223):507-513

4. Huang CL, Wang YM, Li XW et al (2020) Clinical features of patients infected with 2019 novel coronavirus in Wuhan, China [J]. Lancet 395(10223):497-506

5. Gandhi RT, Lynch JB, Rio CD (2020) Mild or Moderate Covid-19 [J]. N Engl J Med 383(18):1757-1766

6. Berlin DA, Solomon CG, Gulick RM et al (2020) Severe Covid-19 [J]. New England Journal of Medicine

7. Singh AK, Gillies CL, Singh R et al (2020) Prevalence of comorbidities and their association with mortality in patients with COVID-19: a systematic review and meta-analysis [J]. Diabetes Obes Metab 22(10):1915-1924

8. Sarnak MJ, Jaber BL (2001) Pulmonary infectious mortality among patients with end-stage renal disease $[\mathrm{J}]$. Chest 120:1883-1887

9. Henry BM, Lippi G (2020) Chronic kidney disease is associated with severe coronavirus disease 2019 (COVID-19) infection [J]. Int Urol Nephrol 52(6):1193-1194

10. Cheng Y, Luo R, Wang K et al (2020) Kidney disease is associated with in-hospital death of patients with COVID-19 [J]. Kidney Int 97(5):829-838

11. Liberati A, Altman DG, Tetzlaff J et al (2009) The PRISMA statement for reporting systematic reviews and meta-analyses of studies that evaluate healthcare interventions: explanation and elaboration [J]. BMJ 339:b2700

12. Wells GA, Shea B, O'Connell D et al (2014) The NewcastleOttawa Scale (NOS) for assessing the quality of nonrandomised studies in meta-analyses [J]. Ottawa Health Research Institute Web site 
13. Zhou F, Yu T, Du R et al (2020) Clinical course and risk factors for mortality of adult inpatients with COVID-19 in Wuhan, China: a retrospective cohort study [J]. Lancet 395(10229):1054-1062

14. Yan Y, Yang Y, Wang F et al (2020) Clinical characteristics and outcomes of patients with severe covid-19 with diabetes [J]. BMJ Open Diabetes Res Care 8(1):e001343

15. Wang L, He W, Yu X et al (2020) Coronavirus disease 2019 in elderly patients: characteristics and prognostic factors based on 4-week follow-up [J]. J Infect 80(6):639-645

16. Wang D, Yin Y, Hu C et al (2020) Clinical course and outcome of 107 patients infected with the novel coronavirus, SARS-CoV-2, discharged from two hospitals in Wuhan, China [J]. Crit Care 24(1): 188

17. Shi S, Qin M, Cai Y et al (2020) Characteristics and clinical significance of myocardial injury in patients with severe coronavirus disease 2019 [J]. Eur Heart J 41(22):2070-2079

18. Shi Q, Zhang X, Jiang F et al (2020) Clinical characteristics and risk factors for mortality of COVID-19 patients with diabetes in wuhan, China: a two-center, retrospective study [J]. Diabetes Care 43(7):1382-1391

19. Ruan Q, Yang K, Wang M et al (2020) Correction to: clinical predictors of mortality due to COVID-19 based on an analysis of data of 150 patients from Wuhan, China [J]. Intensive Care Med 46(6):1294-1297

20. Nikpouraghdam M, Farahani AJ, Alishiri G et al (2020) Epidemiological characteristics of coronavirus disease 2019 (COVID19) patients in IRAN: a single center study [J]. J Clin Virol 127:104378

21. Chen T, Wu D, Chen H et al (2020) Clinical characteristics of 113 deceased patients with coronavirus disease 2019: retrospective study [J]. BMJ 368:m1091
22. Chen T, Dai Z, Mo P et al (2020) Clinical characteristics and outcomes of older patients with coronavirus disease 2019 (COVID19) in Wuhan, China (2019): a single-centered, retrospective study [J]. J Gerontol A Biol Sci Med Sci 75(9):1788-1795

23. Cao J, Tu WJ, Cheng W et al (2020) Clinical features and shortterm outcomes of 102 patients with corona virus disease 2019 in Wuhan, China [J]. Clin Infect Dis 71(15):748-755

24. Banerjee A, Pasea L, Harris S et al (2020) Estimating excess 1-year mortality associated with the COVID-19 pandemic according to underlying conditions and age: a population-based cohort study [J]. Lancet 395(10238):1715-1725

25. Bikbov B, Purcell CA, Levey AS et al (2020) Global, regional, and national burden of chronic kidney disease, 1990-2017: a systematic analysis for the Global Burden of Disease Study 2017 [J]. Lancet 395(10225):709-733

26. Kessler M, Hoen B, Mayeux D et al (1993) Bacteremia in patients on chronic hemodialysis [J]. Nephron 64(1):95-100

27. Betjes MG (2013) Immune cell dysfunction and inflammation in end-stage renal disease [J]. Nat Rev Nephrol 9(5):255-265

28. Lee JY, Kim HA, Huh K et al (2020) Risk factors for mortality and respiratory support in elderly patients hospitalized with COVID19 in Korea [J]. J Korean Med Sci 35(23):e223

29. Li R, Li SR, Du XB et al (2020) Clinical observations in the very elderly patients with COVID-19 in Wuhan [J]. Geriatr Gerontol Int 20(7):709-714

Publisher's Note Springer Nature remains neutral with regard to jurisdictional claims in published maps and institutional affiliations. 